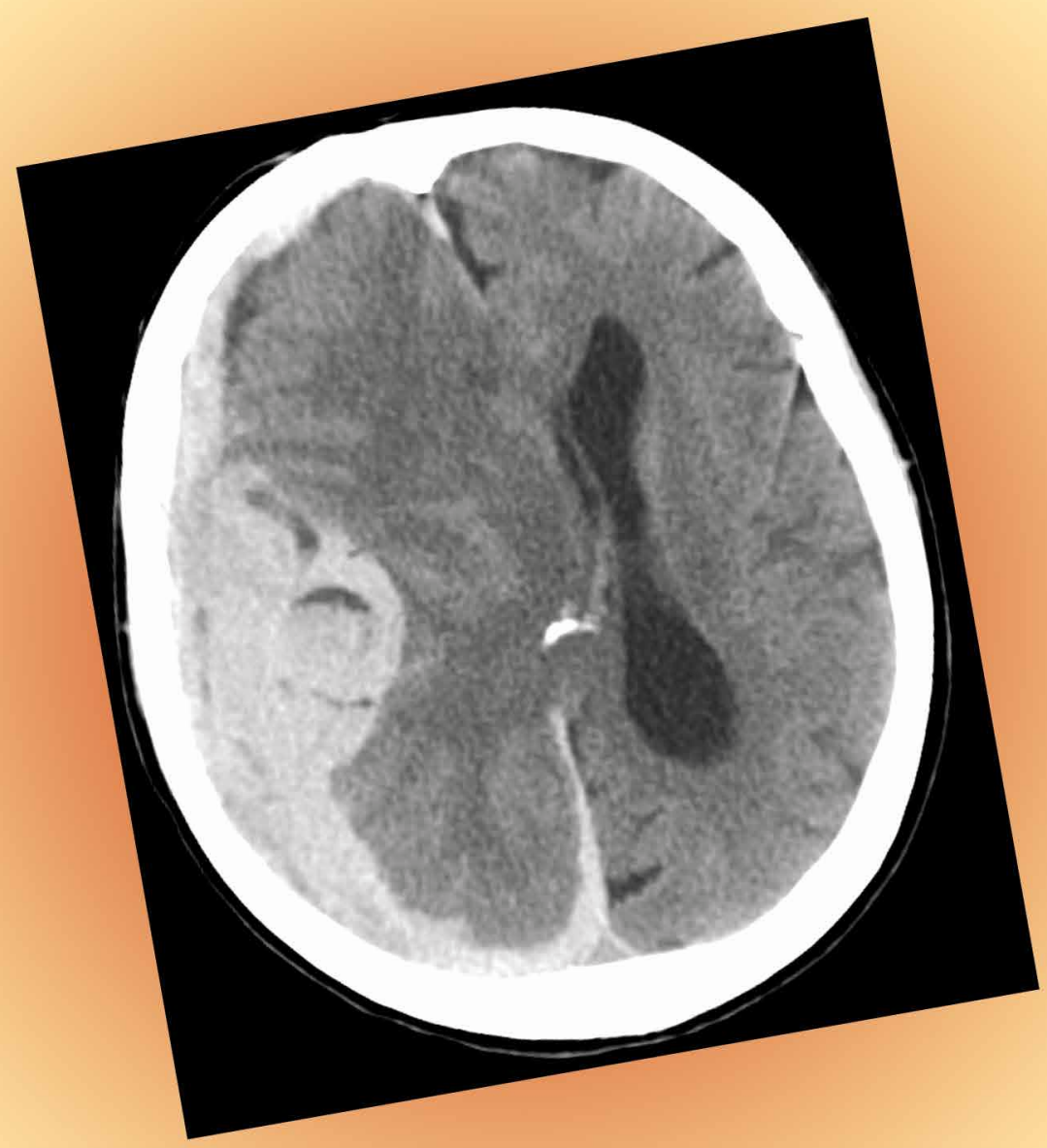




\section{Geriatric Trauma Patients and Altered Mental Status}

Catherine A. Marco, MD; Ashlee Edgell, BS; Catherine Eggers, BS;

Christopher Fagan, BS; James E. Olson, $\mathrm{PhD}$

\section{Through a case presentation and results of a retrospective chart-review study, the authors outline common causes of trauma and altered mental status in geriatric patients.}

\section{Case}

A 76-year-old woman presented to the ED with right rib pain after tripping on a rug and sustaining a fall down the stairs in her home. The patient's chart review showed a history of multiple falls over the past year, with injuries including left rib fracture, right distal radius fracture, ankle sprain, forehead contusion, and left hip contusion. Regarding her social history, the patient denied any alcohol or drug use. She was not on any prescription medications and had no known medication or food allergies.

The physical examination was notable for a thin, white female in no apparent distress. The patient's vital signs at presentation were: temperature, $97.2^{\circ} \mathrm{F}$; blood pressure, 110/78 $\mathrm{mm} \mathrm{Hg}$; heart rate, 110 beats/minute; respiratory rate, 24 breaths/ minute. She was somnolent but arousable and oriented to person, place, and time. The right chest wall was tender, and her lungs were clear to auscultation. The cardiac and neurological examinations were within normal limits. The patient had multiple contusions of various stages of healing over all extremities.

\section{Introduction}

Geriatric patients aged 65 years and older represent a large, growing segment of the US population and, according to US Census Bureau data, represent an estimated $14 \%$ of the population. ${ }^{1}$ Moreover, this population accounts for $36 \%$ of all ambulance transports, $25 \%$ of hospitalizations, and $25 \%$ of total trauma costs. ${ }^{2}$ Although geriatric patients are less likely to be involved in trauma compared with other age groups, they are more likely to have fatal outcomes when injured. Approximately $28 \%$ of deaths due to accidental causes involve persons aged 65 and older. The highest mortality rates from trauma are noted in patients in the 8 th decade and older. ${ }^{3}$

Dr Marco is a professor of emergency medicine and surgery, Wright State University Boonshoft School of Medicine, Kettering, Ohio; and an emergency physician at Miami Valley Hospital, Dayton, Ohio. Ms Edgell, Ms Eggers, and Mr Fagan are students at Wright State University Boonshoft School of Medicine, Dayton, Ohio. Dr Olson is the director of the research laboratory and professor of emergency medicine at Wright State University Boonshoft School of Medicine, Kettering, Ohio.

DOI: 10.12788/emed.2016.0002 
Table 1. Altered Mental Status Among Trauma Patients

\begin{tabular}{lc} 
Etiology & Diagnostic Tests \\
\hline $\begin{array}{l}\text { Trauma } \\
\text { Intracranial hemorrhage }\end{array}$ & \\
Shock/Hypovolemia with hypotension & CT of brain, noncontrast \\
Metabolic etiologies & Blood pressure \\
\hline Electrolyte abnormality & \\
Hypoglycemia & Serum chemistry panel \\
Hyperglycemia & Point-of-care glucose \\
Hyperammonemia & Point-of-care glucose \\
Hypoxia & Serum ammonia level \\
Uremia & Pulse oxygenation \\
\hline
\end{tabular}

\section{Medication/Drugs}

Alcohol intoxication

Illicit drug use (opiates, cocaine, marijuana, benzodiazepines, other)

Alcohol level

Toxicology screen

Pharmaceutical adverse effects (narcotics, benzodiazepines, etc)

History and physical examination

Withdrawal syndromes

History and physical examination

\section{Malignancy}

Intracranial mass

CT of brain

\section{Seizure}

\section{Endocrine}

Hypothyroidism

Hyperthyroidism

Adrenal insufficiency

\section{Temperature}

Hypothermia

Hyperthermia
EEG, serum lactate

TSH, Free T4

TSH, Free T4

ACTH stimulation test

\section{Temperature}

Temperature

\section{Psychiatric Conditions}

History and physical examination

Abbreviations: ACTH, adrenocorticotropic hormone; CT, computed tomography; EEG, electroencephalogram; T4, thyroxine;

$\mathrm{TSH}$, thyroid-stimulating hormone.

Mechanism of Injury and

Preexisting Conditions

Falls are the most common mechanism of injury in patients over age 65 years, ${ }^{4}$ and mortality as a result of falls increases with advanced age. ${ }^{5}$ In addition to the increased risk of trauma, comorbid diseases are also common in this population and include diabetes mellitus, coronary artery disease, arthritis, renal disease, and pulmonary disease. $^{6}$

The presence of preexisting conditions, which affect a patient's physiological age, is associated with increased mortality rates. ${ }^{7,8}$ As with other age groups, outcomes for geriatric trauma patients can 
Table 2. Mode of Arrival and Mechanism of Injury of 144 Geriatric Trauma Patients ${ }^{10}$

\begin{tabular}{llcc}
\hline Variable & & $\mathbf{N}$ & $\%$ \\
\hline Mode of arrival & Walk-in & 5 & 3.47 \\
& Ambulance & 101 & 70.14 \\
& Helicopter & 38 & 26.39 \\
\hline Injury mechanism & Assault & 3 & 2.08 \\
& Motorcycle accident & 1 & 0.69 \\
& Fall & 106 & 73.61 \\
& Motor vehicle collision & 26 & 18.06 \\
& Other & 7 & 4.86 \\
\hline
\end{tabular}

also be predicted using the Injury Severity Score. ${ }^{9}$ Conditions associated with altered mental status in the geriatric trauma population and are listed in Table 1.

\section{Review Data}

Geriatric trauma patients frequently present with altered mental status. An understanding of potential etiologies of altered mental status is important to the ED diagnosis and management.

The issue of traumatic injury in the aging population was studied at the authors' institution through a retrospective chart review at the ED of Miami Valley Hospital, Dayton, Ohio, an urban hospital with an annual patient census of 95,000 visits. ${ }^{10}$ This study was approved by the Wright State University Institutional Review Board (IRB) and the Miami Valley Hospital Human Investigation and Research Committee (HIRC).

The study included 1,077 geriatric trauma patients, 144 of whom had a Glasgow Coma Score (GCS) of 14 or lower $(13.4 \%)$. Fifty-four percent of the patients were male. Most (88.19\%) of the patients were white, $9.72 \%$ were black, $0.69 \%$ were Hispanic, and $1.39 \%$ were of other ethnicities. The median patient age was 78.5 \pm 7.81 (SD). Forty-two percent of patients were transferred to Miami Valley Hospital from another institution. The mode of arrival and mechanism of injury are outlined in Table 2. The most common mode of arrival was ambulance $(n=101)$, followed by helicopter $(\mathrm{n}=38)$, and walk-in $(\mathrm{n}=5)$. Fall ( $=106)$ and motor vehicle collision $(n=26)$ were the most common mechanisms of injury. The most common comorbid medical conditions were hypertension $(56 \%)$ and heart disease (49\%; Table 3).

\section{Laboratory Findings}

Hyperglycemia ( $n=121$ ) was the most common laboratory abnormality seen in patients, followed by anemia $(n=71)$, sodium abnormalities ( $\mathrm{n}=13)$, and hypoglycemia $(\mathrm{n}=4)$. The most common finding on brain computed tomography (CT) was subdural hemorrhage $(\mathrm{n}=55$; Table 4). The results of both alcohol and urine toxicology screens are outlined in Table 5. In this study, 82 patients were not tested for alcohol intoxication, and 109 patients did not have a urine toxicology screen. Of the patients tested for alcohol intoxication, $20 \%$ had an alcohol level greater than $80 \mathrm{mg} / \mathrm{mL}$ (legal limit for operating a motor vehicle in the state of Ohio). There was no significant association between alcohol level and age, gender (Fisher's exact test, $P=.49$ ), or ethnicity (Fisher's exact test, $P=.08$ ). Opiates were the most commonly found substance in patients tested viaaurine toxicology screen. 
Table 3. Comorbid Conditions Among 144 Geriatric Trauma Patients ${ }^{10}$

\begin{tabular}{lcc}
\hline Comorbid Condition & Frequency in Sample & \% of Sample \\
\hline CNS/seizures, etc & 39 & 27.08 \\
\hline Cardiac/MI/angina/cardiomyopathy/MVP, etc & 71 & 49.31 \\
\hline Diabetes & 39 & 27.08 \\
\hline Gl/diverticulitis/hiatal hernia/reflux, etc & 18 & 12.50 \\
\hline Hypertension & 80 & 55.56 \\
\hline Malignancy (any type) & 18 & 12.50 \\
\hline Pulmonary/asthma/COPD/bronchitis & 24 & 16.67 \\
\hline Renal/renal failure/UTI, etc & 14 & 9.72 \\
\hline Other & 54 & 37.50 \\
\hline
\end{tabular}

Abbreviations: CNS; central nervous system; COPD, chronic obstructive pulmonary disease; Gl, gastrointestinal; MI, myocardial infarction; MVP, mitral valve prolapse; UTI, urinary tract infection.

Table 4. Computed Tomography Results of Geriatric Trauma Patients ${ }^{10}$

\begin{tabular}{lcc}
\hline Computed Tomography Result & Frequency in Sample & \% of Sample \\
\hline Subarachnoid hemorrhage & 44 & 30.56 \\
\hline Cerebrovascular accident & 6 & 4.17 \\
\hline Epidural hemorrhage & 6 & 4.17 \\
\hline Intraparenchymal hemorrhage & 23 & 15.97 \\
\hline Subdural hemorrhage & 55 & 38.19 \\
\hline Normal & 53 & 36.81 \\
\hline
\end{tabular}

\section{Mortality}

Although traumatic injury is a common presentation among geriatric emergency patients, this population is overall less likely to be involved in a traumatic event compared to other age groups. However, when injured, geriatric trauma patients are more likely to have fatal outcomes.

As previously noted, falls are the most common mechanism of injury in patients older than age 65 years. The trend of fallrelated mortality increases with advanced age. It has been estimated that $36 \%$ of geriatric patients who fall will require a repeat ED visit or will die within 1 year following the fall. ${ }^{11}$ Previous reports have demonstrated that mortality is associated with advanced age, injury severity score, shock index, transfusion, head injury, hypotension, and treatment site. ${ }^{12-16}$ 
Table 5. Alcohol Intoxication and Urine Toxicology Screen Among Geriatric Trauma Patients ${ }^{10}$

\begin{tabular}{llcc}
\hline Variable & Result & N & $\%$ \\
\hline Alcohol intoxication & No $(\mathrm{ETOH} \leq 80)$ & 49 & 34.27 \\
& Yes $(\mathrm{ETOH}>80)$ & 12 & 8.39 \\
& Not tested & 82 & 57.34 \\
\hline Urine toxicology screen & None detected & 24 & 17.14 \\
& Opiates & 4 & 2.86 \\
& Opiates/benzodiazepines & 2 & 1.43 \\
& Opiates/antidepressants & 1 & 0.71 \\
& Not tested & 109 & 77.86 \\
\hline
\end{tabular}

Abbreviation: $\mathrm{ETOH}$, ethyl alcohol.

\section{Cerebral Hemorrhage}

In the study conducted at the authors' institution, most patients receiving a head CT scan had at least one abnormality. ${ }^{10}$ Subdural hemorrhage was the most commonly reported abnormality followed by subarachnoid and intraparenchymal hemorrhages, respectively. ${ }^{10}$

Falls are a common cause of intracranial hemorrhage, and $30 \%$ to $40 \%$ of patients over age 65 years will experience at least one fall each year. ${ }^{17}$ Consistent with these statistics, fall was the most common mechanism of injury in the patient population at the authors' institution. Intracranial hemorrhage can cause altered mental status by increasing the intracranial pressure and decreasing the cerebral perfusion pressure. These abnormalities are often amenable to medical and/or surgical treatment if identified in time. ${ }^{18}$

\section{Hyperglycemia}

Hyperglycemia was one of the most common diagnostic test abnormalities associated with altered mental status in the authors' study. ${ }^{10}$ Although increased blood glucose is part of the stress response to injury, geriatric patients experience a higher incidence of stress hyperglycemia and are unable to mount an adequate insulin response in trauma. ${ }^{19,20}$ High-glucose levels are associated with significantly higher mortality rates among trauma patients. ${ }^{21-24}$

\section{Alcohol Intoxication}

Alcohol intoxication was common among the patients in the author's study. ${ }^{10}$ In contrast, a smaller percentage of patients were tested and found to be positive for opioids or benzodiazepines. The risk of a traumatic brain injury (TBI) increases significantly if the patient sustained the injury while under the influence of alcohol. ${ }^{25}$ Alcohol increases the mortality after trauma especially in patients over the age of $40 .{ }^{26}$ Alcohol-related TBIs are associated with poorer outcomes with increasing age. ${ }^{27}$ Falls at ground level after alcohol consumption are associated with more casualties than nonalcohol-related falls. ${ }^{28,29}$

\section{Differential Diagnosis}

As the case in this review illustrates, among geriatric trauma patients with altered mental status, the most common mechanism of injury is fall. The differential diagnosis should be considered, including intracranial hemorrhage, alcohol intoxication, nonprescription drug use, prescriptiondrug effects, infection, and/or metabolic or endocrine disorders. Appropriate laboratory and radiographic tests should be obtained, and may include CT of the brain 


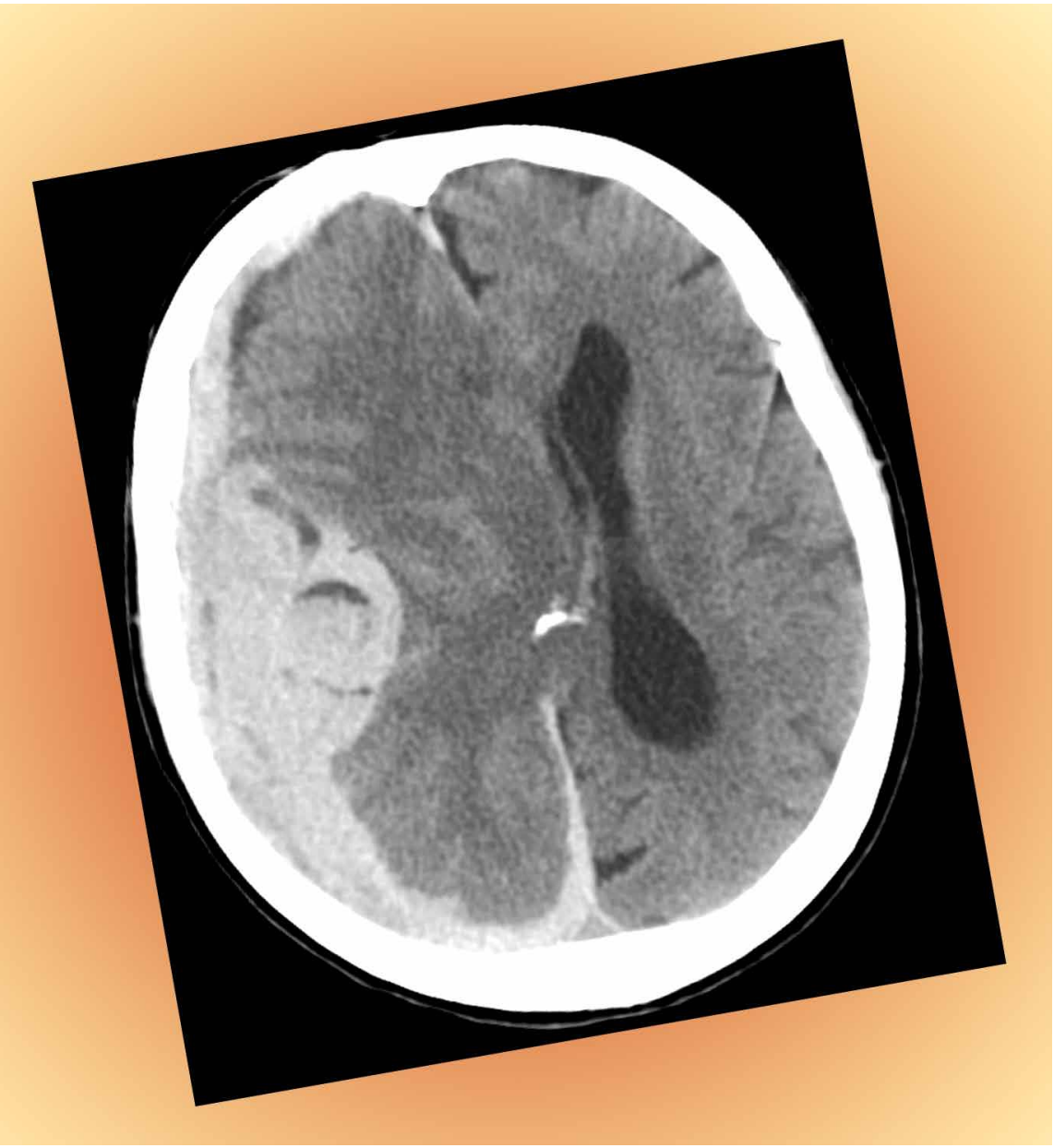

and cervical spine, chemistry profile, complete blood count, chest X-ray, urinalysis, alcohol level, and toxicology screen.

\section{Conclusion}

This case represents one of many common presentations of trauma among geriatric patients. There was evidence of multiple falls by chart review and physical examination. Evidence of multiple traumatic events of various stages should raise the suspicion of neurological deficits, substance or prescription-medication effects, or physical abuse of the elderly patient. The ED workup should include brain CT, electrolytes, complete blood count, chest radiograph, and urinalysis. The patient should be admitted for observation and workup for medical and traumatic etiologies of multiple falls. When discharged, home-health services or rehabilitation services should be considered.

The results of the authors' chart-review study confirmed that falls are the most common mechanism of injury in geriatric trauma patients presenting to the ED with altered mental status. ${ }^{10}$ The most common diagnostic test abnormalities associated with altered mental status in this study included hyperglycemia, abnormal CT results, anemia, and alcohol intoxication. Future studies are needed to access relations between ethanol or opioid intoxication and the presence of positive CT findings to guide clinicians' judgment when ordering CT scans and other tests.

\section{References}

1. The United States Census Bureau. Quick Facts. New Jersey. http://www.census.gov/quickfacts/table/ PST045214/34,00 Accessed May 20, 2015.

2. Schwab CW, Kauder DR: Trauma in the geriatric patient. Arch Surg. 1992;127(6):701-706.

3. Ley EJ, Clond MA, Hussain ON, et al. Mortality by decade in trauma patients with Glascow Coma Scale 3. Am Surg. 2011;77(10):1342-1345.

4. Smith DP, Enderson BL, Maull KI. Trauma in the elderly: determinants of outcome. South Med J. 1990;83(2):171-177.

5. Sise RG, Calvo RY, Spain DA, Weiser TG, Staudenmayer KL. The epidemiology of trauma-related mortality in the United States from 2002 to 2010. J Trauma Acute Care Surg. 2014;76(4):913-919; discussion 920 .

6. Morris JA, MacKenzie EJ, Edelstein SL. The effect of preexisting conditions on mortality in trauma patients. JAMA. 1990;263(4):1942-1946.

7. Morris JA, MacKenzie EJ, Damiano AM, Bass SM. Mortality in trauma patients: the interaction between host factors and severity. J Trauma. 1990;30(12): 1476-1482.

8. Milzmann DP, Boulanger BR, Rodriguez A, Soderstrom CA, Mitchell KA, Magnant CM. Pre-existing disease in trauma patients: a predictor of fate independent of age and injury severity score. J Trauma. 1992;32(2):236-243.

9. Knudson MM, Lieberman J, Morris JA Jr, Cushing $\mathrm{BM}$, Stubbs HA. Mortality factors in geriatric blunt trauma patients. Arch Surg. 1994;129(4):448-453.

10. Edgell A, Eggers C, Fagan C, Olson J, Marco CA. Altered mental status among geriatric trauma patients. Poster presented at: Wright State University Boonshoft School of Medicine Seventh Annual Medical Student Research Symposium: Celebrating Medical Student Scholarship; April 8, 2015; Dayton, Ohio. Poster 22. http://corescholar.libraries.wright.edu/ cgi/viewcontent.cgi?article=1006\&context=ra_symp. Accessed December 17, 2015. 
11. Liu SW, Obermeyer Z, Chang Y, Shankar KN. Frequency of ED revisits and death among older adults after a fall. Am J Emerg Med. 2015;33(8):1012-1018.

12. Zhao FZ, Wolf SE, Nakonezny PA, et al. Estimating geriatric mortality after injury using age, injury severity, and performance of a transfusion: the Geriatric Trauma Outcome score. J Palliat Med. 2015;18(8):677-681.

13. Tornetta P 3rd, Mostafavi H, Riina J, et al. Morbidity and mortality in elderly trauma patients. J Trauma. 1999;46(4):702-706.

14. Meldon SW, Reilly M, Drew BL, Mancuso C, Fallon W Jr. Trauma in the very elderly: a community-based study of outcomes at trauma and nontrauma centers. J Trauma. 2002;52(1):79-84.

15. Hashmi A, Ibrahim-Zada I, Rhee P, et al. Predictors of mortality in geriatric trauma patients: a systematic review and meta-analysis. J Trauma Acute Care Surg. 2014;76(3):894-901.

16. Pandit V, Rhee P, Hashmi A, et al. Shock index predicts mortality in geriatric trauma patients: an analysis of the National Trauma Data Bank. J Trauma Acute Care Surg. 2014;76(4):1111-1115.

17. Ambrose AF, Paul G, Hausdorff JM. Risk factors for falls among older adults: a review of the literature. Maturitas. 2013;75(1):51-61.

18. Kolias AG, Guilfoyle MR, Helmy A, Allanson J, Hutchinson PJ. Traumatic brain injury in adults. Pract Neurol. 2013;13(4):228-235.

19. Kerby JD, Griffin RL, McLennan P, Rue LW 3rd. Stress-induced hyperglycemia, not diabetic hyperglycemia is associated with higher mortality in trauma. Ann Surg. 2012;2256(3):446-452.

20. Paladino L, Subramania RA, Nabors S, Bhardwaj S,
Sinert R. Triage hyperglycemia as a prognostic indicator of major trauma. J Trauma. 2010;69(1):41-45

21. Desai D, March R, Watter JM. Hyperglycemia after trauma increases with age. J Trauma. 1989;29(6): 719-723.

22. McCowen KC, Malhotra A, Bistrian BR. Stressinduced hyperglycemia. Crit Care Clin. 2001;17(1): 107-124.

23. Liu-DeRyke X, Collingridge DS, Orme J, Roller D, Zurasky J, Rhoney DH. Clinical impact of early hyperglycemia during acute phase of traumatic brain injury. Neurocrit Care. 2009;11(2):151-157.

24. Laird AM, Miller PR, Kilgo PD, Meredith JW, Chang MC. Relationship of early hyperglycemia to mortality in trauma patients. J Trauma. 2004;56(5):1058-1062.

25. Salim A, Hadjizacharia P, Dubose J, et al. Persistent hyperglycemia in severe traumatic brain injury: an independent predictor of outcome. Am Surg 2009;75(1): 25-29.

26. Vaaramo K, Puljula J, Tetri S, Juvela S, Hillbom $\mathrm{M}$. Head trauma sustained under the influence of alcohol is a predictor for future traumatic brain injury: a long-term follow up study. Eur J Neurol. 2014;21(2):293-298.

27. Kowalenko T, Burgess B, Szpunar SM, Irvin-Babcock CB. Alcohol and trauma--in every age group. Am J Emerg Med. 2013;31(4):705-709.

28. Chen CM, Yi HY, Yoon TH, Dong C. Alcohol use at time of injury and survival following traumatic brain injury: results from the National Trauma Data Bank. J Stud Alcohol Drugs. 2012;73(4):531-541.

29. Thierauf A, Preuss J, Lignitz E, Madea B. Retrospective analysis of fatal falls. Forensic Sci Int. 2010;198(1-3):92-96 